\title{
Seasonal and diurnal variations in ultraviolet-B and ultraviolet-A irradiances at and below the sea surface at Helgoland (North Sea) over a 6-year period
}

Received: 28 February 2000 / Received in revised form: 3 July 2000 / Accepted: 10 July 2000 / Published online: 6 February 2001 (C) Springer-Verlag and AWI 2001

\begin{abstract}
Ultraviolet (UV) radiation at four wavelengths $(305,320,340$ and $380 \mathrm{~nm})$ and photosynthetically active radiation (PAR) were measured from May 1994 to October 1999 using Biospherical UV radiometers. A surface reference sensor located on the roof of the Marine Station at Helgoland recorded values every $5 \mathrm{~min}$, and an equivalent profiling underwater sensor was used for measurements in the sea at approximately monthly intervals. The ratio of $305-\mathrm{nm}$ radiation to PAR varied seasonally, with a 14-fold increase from winter to summer. A much weaker seasonal trend (ca. 1.5-fold) was apparent in the ratio of $320-\mathrm{nm}$ radiation to PAR, but there was no seasonal trend in the ratios of $340-$ or $380-\mathrm{nm}$ radiation to PAR. The year-to-year variations in 305-nm radiation were also much greater relative to PAR than for the other UV wavelengths, but there was no evidence of a change in the $305 \mathrm{~nm}$ :PAR ratio over the study period. The ratios of both 305- and 320-nm radiation to PAR increased from dawn to midday, but those of 340- and 380 -nm radiation were almost constant through the day, except shortly before sunrise and after sunset when the proportions of 340- and 380-nm radiation increased. Underwater measurements of PAR and UV suggest that the $1 \%$ depth for 305-nm radiation was little more than $1 \mathrm{~m}$, but this estimate is valid only for summer and autumn because, in other seasons, few reliable readings for 305-nm radiation could be obtained underwater, and no attenuation coefficient could be calculated. The $1 \%$ depths recorded for the other UV wavelengths in the middle 6 months of the year were $2.0 \mathrm{~m}$ for $320 \mathrm{~nm}$, $2.6 \mathrm{~m}$ for $340 \mathrm{~nm}$ and $4.6 \mathrm{~m}$ for $380 \mathrm{~nm}$, compared with $12 \mathrm{~m}$ for PAR, but the attenuation of all wavebands in-
\end{abstract}

Communicated by K. Lüning

M.J. Dring $(\varangle) \cdot$ A. Wagner $\cdot$ L.A. Franklin · R. Kuhlenkamp K. Lüning Biologische Anstalt Helgoland, 27498 Helgoland, Germany

Present address:

M.J. Dring, Queen's University Marine Laboratory, Portaferry, County Down BT22 1PF, Northern Ireland, UK e-mail: m.dring@qub.ac.uk creased sharply in October and remained higher until March. An analysis of the influence of sun angle, total column ozone concentration, the proportion of skylight, and cloud cover on the ratio of UV wavelengths to PAR in surface irradiance demonstrated that solar angle has a greater influence than ozone concentration on the irradiance at $305 \mathrm{~nm}$, and that the typical occurrence of ozone "holes" in spring may not result in higher UV-B irradiances than occur under higher ozone concentrations in summer. The implications of the data for attempts to model the biological effects of natural UV radiation on marine organisms are considered.

\section{Introduction}

The influence of ultraviolet-B radiation (UV-B; $280-315 \mathrm{~nm}$ ) on living organisms has been extensively studied since the realisation that anthropogenic inputs to the atmosphere were causing significant reductions in stratospheric ozone concentrations, and that these were permitting higher proportions of the UV-B in natural solar radiation to penetrate to the surface of the earth [for a recent review of UV-B effects on marine macrophytes, see Franklin and Forster (1997)]. Since the greatest reductions in ozone concentration that have been observed so far have been over Antarctica, particular attention has been focussed on monitoring UV radiation in the Antarctic (Booth et al. 1994; Roy et al. 1994), but reports of thinning of the ozone layer over the Arctic and northern Europe have emphasised the importance of also studying the effects of UV-B on Nordic marine ecosystems (Wängberg et al. 1996). The monitoring of UV radiation levels at the sea surface near Helgoland and its penetration through seawater, which is reported in the present paper, forms part of a broad survey of the influence of UV-A (320-400 nm) and UV-B radiation on a wide range of marine species from the southern North Sea. 


\section{Materials and methods}

UV and visible radiation were measured using UV radiometers (Biospherical Instruments, San Diego, Calif.). A surface reference sensor (PUV-510) was located on the roof of Haus C of the Marine Station at Helgoland $\left(54^{\circ} 12^{\prime} \mathrm{N}, 7^{\circ} 54^{\prime} \mathrm{E}\right)$, and linked permanently to a PC. The irradiance at four UV wavelengths $(305,320$, 340 and $380 \mathrm{~nm}$; half-bandwidths 7-11 nm) and of photosynthetically active radiation (PAR) was recorded continuously at 5-min intervals over a period of 5.5 years (May 1994-October 1999), with the exception of 3 months when the sensor was recalibrated (January-March 1999). The recalibration of the sensor by Biospherical Instruments in 1999 showed that the drift of amplitude in each waveband was $+6 \%$ for $305 \mathrm{~nm},+4 \%$ for $320 \mathrm{~nm},-4 \%$ for $340 \mathrm{~nm},+5.5 \%$ for $380 \mathrm{~nm}$, and $+2.3 \%$ for PAR. Errors of this magnitude were considered acceptable, and no corrections have been made for them. Daily integrals of the individual readings in each waveband were calculated and corrected by the values registered by each sensor in the dark to estimate the total radiation received over each 24 -h period. The maximal values registered for each waveband on each day were also recorded. In order to calculate the ratio between the UV wavelengths and PAR in absolute units, the values recorded for UV radiation in $\mathrm{mW} \mathrm{m}^{-2} \mathrm{~nm}^{-1}$ were converted to $\mu \mathrm{mol} \mathrm{m} \mathrm{m}^{-2} \mathrm{~s}^{-1} \mathrm{~nm}^{-1}$.

Values for the total column ozone (in Dobson units) on specific days at Helgoland in the period August 1996-October 1999 were obtained from the NASA website (http://jwocky.gsfc.nasa.gov/) by entering the latitude and longitude of Helgoland.

Depth profiles of irradiance in the same wavebands in the sea within $1 \mathrm{~km}$ of Helgoland were measured at approximately monthly intervals over the same time period with a profiling underwater sensor (PUV-500; Biospherical Instruments). This sensor recorded the irradiance at each wavelength and depth every $2 \mathrm{~s}$, and data were obtained continuously as the sensor was lowered and raised for each profile. An attenuation coefficient was then calculated for each waveband by fitting a linear regression to the logarithm of the irradiance values against depth. The profiles were always measured in the middle of the day and on bright, calm days to maximise the depth range of readings at the shorter wavelengths and to improve the reliability of the attenuation coefficient that was calculated. Even so, it was not possible to obtain reliable readings for the underwater irradiance at $305 \mathrm{~nm}$ during the winter months (November-March, inclusive), so that the attenuation coefficient for this wavelength could not be estimated for this period of the year.

\section{Results}

The total radiation incident upon the surface sensor on each day (the daily integral) was calculated from the sum of the irradiance measurements, corrected for dark readings. The annual course of these daily integrals for the four UV wavelengths and for PAR is shown for a typical year (1997) in Fig. 1, and the means of the daily integrals for each month averaged over the 6 years of the study, together with the maximum and minimum values, are listed in Table 1 . The maximal irradiance values recorded for each waveband on each day were extracted from the data, and these values for a UV-B $(305 \mathrm{~nm})$ and UV-A $(340 \mathrm{~nm})$ wavelength are plotted for the full length of the study in Fig. 2. The means, maximum and minimum values for these daily maxima in each month are also included in Table 1. For all wavebands except $305 \mathrm{~nm}$, the range between the largest and smallest daily integral recorded was 200- to 300-fold, whereas the range for the daily maxima was 100 - to 150 -fold. How-

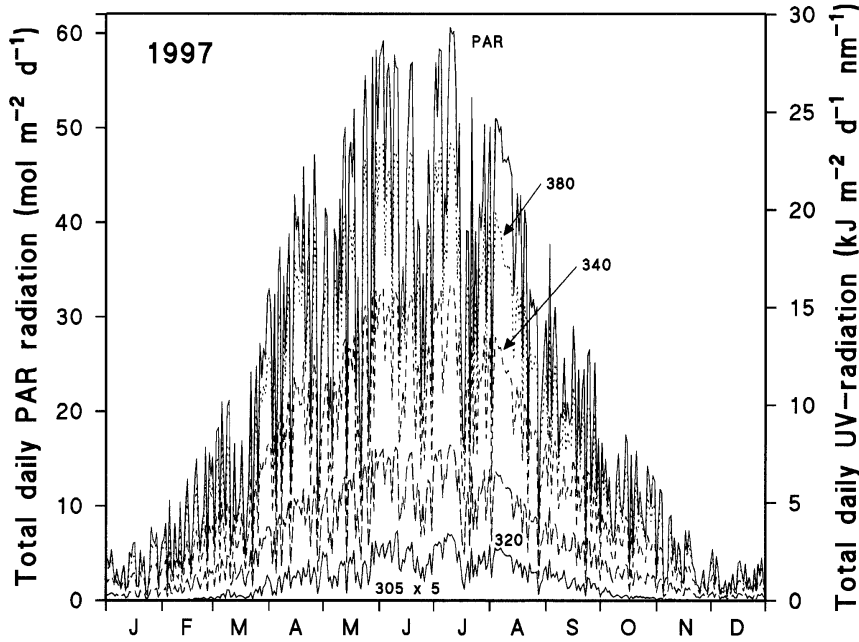

Fig. 1 Daily integrals of radiation in each of four ultraviolet $(U V)$ wavelengths $(305,320,340$ and $380 \mathrm{~nm}$; right-hand axis) and of photosynthetically active radiation (PAR; left-hand axis) at Helgoland in 1997

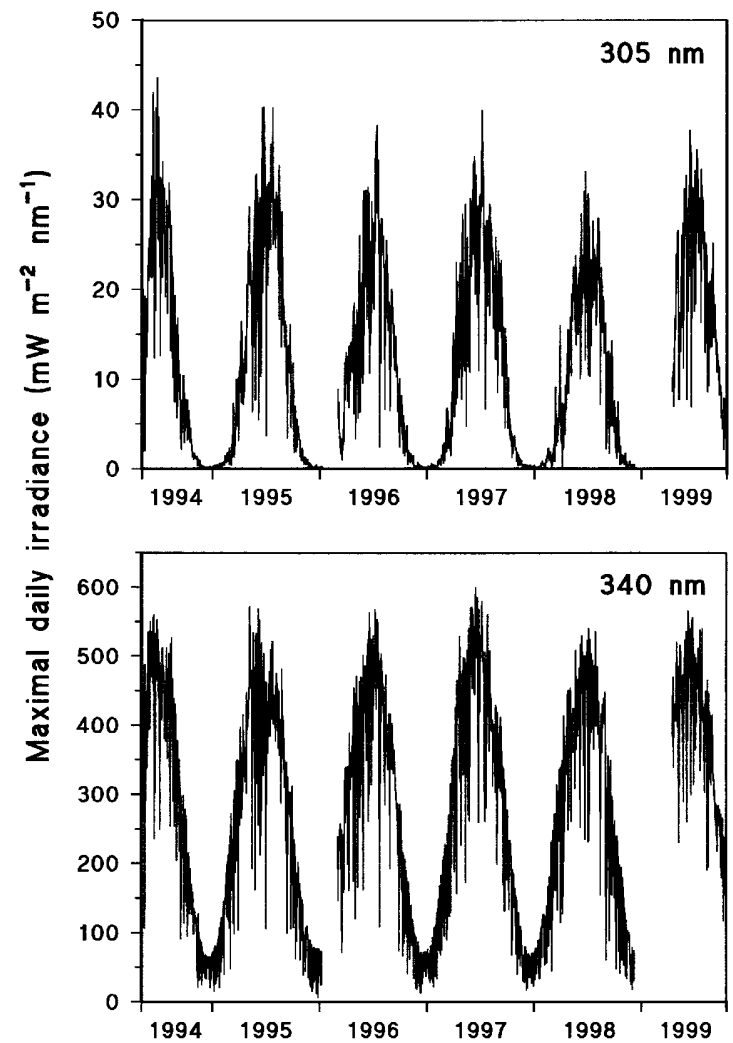

Fig. 2 Maximal irradiance in two UV wavelengths (305 and $340 \mathrm{~nm}$ ) on each day between May 1994 and October 1999 at Helgoland. The two breaks in the record represent periods when the sensor was not operating for technical reasons

ever, the range for both integrals and daily maxima at $305 \mathrm{~nm}$ was much higher, over 10,000-fold for the former and 3,000-fold for the latter (Table 1). The highest values for all wavebands were recorded during May-July, and the lowest values in December. 
Table 1 Mean, maximal and minimal values of daily integrals of radiation and daily maxima of irradiance in each of four ultraviolet $(U V)$ wavelengths $(305,320,340$ and $380 \mathrm{~nm})$ and of photo- synthetically active radiation (PAR) at Helgoland in 1994-1999. Values are given for the whole study, and for each month of the year

\begin{tabular}{|c|c|c|c|c|c|c|c|c|c|c|}
\hline \multirow[t]{2}{*}{ Month } & \multicolumn{5}{|c|}{ Daily integrals } & \multicolumn{5}{|c|}{ Daily maxima } \\
\hline & $\begin{array}{l}\text { PAR } \\
\left(\mathrm{mol} \mathrm{m}^{-2}\right. \\
\left.\mathrm{day}^{-1}\right)\end{array}$ & $\begin{array}{l}305 \mathrm{~nm}^{-2} \\
\left(\mathrm{~kJ} \mathrm{~m}^{-2} \text { day }\right.\end{array}$ & $\begin{array}{r}320 \mathrm{~nm} \\
\left.J^{-1} \mathrm{~nm}^{-1}\right)\end{array}$ & $340 \mathrm{~nm}$ & $380 \mathrm{~nm}$ & $\begin{array}{l}\text { PAR } \\
(\mu \mathrm{mol} \\
\left.\mathrm{m}^{-2} \mathrm{~s}^{-1}\right)\end{array}$ & $\begin{array}{l}305 \mathrm{~nm}^{-2} \\
\left(\mathrm{~mW} \mathrm{~m}{ }^{-2}\right.\end{array}$ & $\begin{array}{c}320 \mathrm{~nm} \\
\left.\mathrm{~nm}^{-1}\right)\end{array}$ & $340 \mathrm{~nm}$ & $380 \mathrm{~nm}$ \\
\hline \multicolumn{11}{|c|}{ January-December } \\
\hline Average & 20.703 & 0.1658 & 2.637 & 5.578 & 8.358 & 1075.38 & 10.491 & 128.30 & 258.42 & 399.92 \\
\hline Maximum & 60.809 & 0.8474 & 8.206 & 16.172 & 23.477 & 2590.11 & 43.552 & 310.06 & 600.06 & 920.07 \\
\hline Minimum & 0.210 & 0.0001 & 0.022 & 0.079 & 0.121 & 17.76 & 0.015 & 1.66 & 5.44 & 8.39 \\
\hline \multicolumn{11}{|l|}{ January } \\
\hline Average & 3.422 & 0.0028 & 0.309 & 0.934 & 1.489 & 311.04 & 0.248 & 23.48 & 65.74 & 108.72 \\
\hline Maximum & 9.659 & 0.0116 & 0.759 & 2.225 & 3.820 & 665.07 & 0.924 & 46.72 & 120.13 & 209.36 \\
\hline Minimum & 0.386 & 0.0001 & 0.052 & 0.172 & 0.262 & 58.36 & 0.050 & 5.73 & 14.82 & 23.65 \\
\hline \multicolumn{11}{|l|}{ February } \\
\hline Average & 7.533 & 0.0112 & 0.762 & 2.008 & 3.151 & 603.03 & 1.004 & 53.05 & 130.62 & 215.58 \\
\hline Maximum & 16.231 & 0.0323 & 1.541 & 3.971 & 6.251 & $1,193.83$ & 2.887 & 94.18 & 230.83 & 410.25 \\
\hline Minimum & 1.375 & 0.0010 & 0.170 & 0.476 & 0.693 & 108.55 & 0.126 & 12.65 & 33.62 & 50.49 \\
\hline \multicolumn{11}{|l|}{ March } \\
\hline Average & 16.299 & 0.0646 & 1.866 & 4.342 & 6.741 & 964.00 & 4.792 & 103.35 & 225.79 & 363.02 \\
\hline Maximum & 33.575 & 0.2562 & 3.941 & 8.691 & 13.518 & $1,691.77$ & 15.992 & 171.23 & 354.04 & 593.06 \\
\hline Minimum & 2.125 & 0.0040 & 0.297 & 0.718 & 1.039 & 135.84 & 0.362 & 19.94 & 44.36 & 64.01 \\
\hline \multicolumn{11}{|l|}{ April } \\
\hline Average & 29.132 & 0.1817 & 3.654 & 7.892 & 12.096 & $1,403.54$ & 12.020 & 175.21 & 353.47 & 551.31 \\
\hline Maximum & 47.126 & 0.4176 & 6.124 & 12.533 & 19.449 & 2210.25 & 24.173 & 260.54 & 529.18 & 839.24 \\
\hline Minimum & 4.480 & 0.0190 & 0.663 & 1.472 & 2.121 & 397.49 & 2.104 & 56.62 & 114.45 & 175.05 \\
\hline \multicolumn{11}{|l|}{ May } \\
\hline Average & 36.796 & 0.3116 & 4.830 & 10.045 & 14.997 & $1,606.47$ & 18.824 & 212.04 & 412.63 & 625.47 \\
\hline Maximum & 58.199 & 0.6420 & 7.733 & 15.846 & 23.477 & $2,590.11$ & 32.836 & 292.11 & 572.65 & 916.04 \\
\hline Minimum & 7.246 & 0.0366 & 1.050 & 2.389 & 3.340 & 363.13 & 1.966 & 44.34 & 106.48 & 155.03 \\
\hline \multicolumn{11}{|l|}{ June } \\
\hline Average & 40.458 & 0.4239 & 5.499 & 11.140 & 16.326 & $1,828.78$ & 25.675 & 243.92 & 465.64 & 697.41 \\
\hline Maximum & 60.377 & 0.8474 & 8.159 & 15.953 & 22.555 & $2,371.95$ & 43.552 & 310.06 & 600.06 & 920.07 \\
\hline Minimum & 9.204 & 0.0855 & 1.523 & 3.069 & 6.869 & 653.17 & 5.405 & 112.18 & 211.23 & 294.85 \\
\hline \multicolumn{11}{|l|}{ July } \\
\hline Average & 41.599 & 0.4455 & 5.564 & 11.182 & 16.318 & $1,787.34$ & 26.199 & 238.85 & 450.87 & 669.42 \\
\hline Maximum & 60.809 & 0.8145 & 8.206 & 16.172 & 22.144 & $2,479.74$ & 40.273 & 307.69 & 579.61 & 894.34 \\
\hline Minimum & 7.304 & 0.0433 & 1.094 & 2.403 & 5.727 & 317.08 & 2.357 & 50.99 & 105.42 & 145.52 \\
\hline \multicolumn{11}{|l|}{ August } \\
\hline Average & 34.735 & 0.3344 & 4.527 & 9.145 & 13.497 & $1,657.16$ & 20.629 & 207.84 & 397.05 & 603.11 \\
\hline Maximum & 52.450 & 0.6123 & 6.777 & 13.511 & 19.138 & 2261.55 & 33.865 & 271.07 & 526.90 & 811.36 \\
\hline Minimum & 6.832 & 0.0596 & 1.124 & 2.316 & 5.152 & 580.65 & 6.388 & 82.37 & 153.89 & 219.12 \\
\hline \multicolumn{11}{|l|}{ September } \\
\hline Average & 20.028 & 0.1558 & 2.583 & 5.328 & 8.009 & $1,209.33$ & 11.451 & 142.58 & 279.56 & 437.54 \\
\hline Maximum & 38.148 & 0.4164 & 4.781 & 9.635 & 13.304 & 1891.95 & 25.175 & 227.68 & 415.47 & 686.48 \\
\hline Minimum & 3.169 & 0.0208 & 0.542 & 1.162 & 2.542 & 183.93 & 1.623 & 31.49 & 60.01 & 85.76 \\
\hline \multicolumn{11}{|l|}{ October } \\
\hline Average & 11.013 & 0.0480 & 1.320 & 2.927 & 4.518 & 841.29 & 4.001 & 84.20 & 178.15 & 293.46 \\
\hline Maximum & 24.016 & 0.1788 & 2.706 & 5.764 & 8.073 & 1478.71 & 11.856 & 133.83 & 286.18 & 485.58 \\
\hline Minimum & 1.768 & 0.0037 & 0.248 & 0.594 & 1.567 & 123.79 & 0.410 & 17.14 & 40.57 & 57.77 \\
\hline \multicolumn{11}{|l|}{ November } \\
\hline Average & 4.677 & 0.0081 & 0.483 & 1.250 & 1.965 & 427.87 & 0.843 & 35.67 & 86.90 & 143.52 \\
\hline Maximum & 11.763 & 0.0255 & 1.111 & 2.724 & 4.514 & 942.28 & 2.246 & 68.31 & 157.29 & 284.69 \\
\hline Minimum & 0.608 & 0.0008 & 0.069 & 0.202 & 0.291 & 54.97 & 0.062 & 6.46 & 17.88 & 26.21 \\
\hline \multicolumn{11}{|l|}{ December } \\
\hline Average & 2.744 & 0.0024 & 0.244 & 0.743 & 1.194 & 264.71 & 0.211 & 19.45 & 54.56 & 90.43 \\
\hline Maximum & 6.193 & 0.0075 & 0.522 & 1.483 & 2.382 & 589.18 & 0.770 & 34.49 & 89.58 & 159.22 \\
\hline Minimum & 0.210 & 0.0001 & 0.022 & 0.079 & 0.121 & 17.76 & 0.015 & 1.66 & 5.44 & 8.39 \\
\hline
\end{tabular}




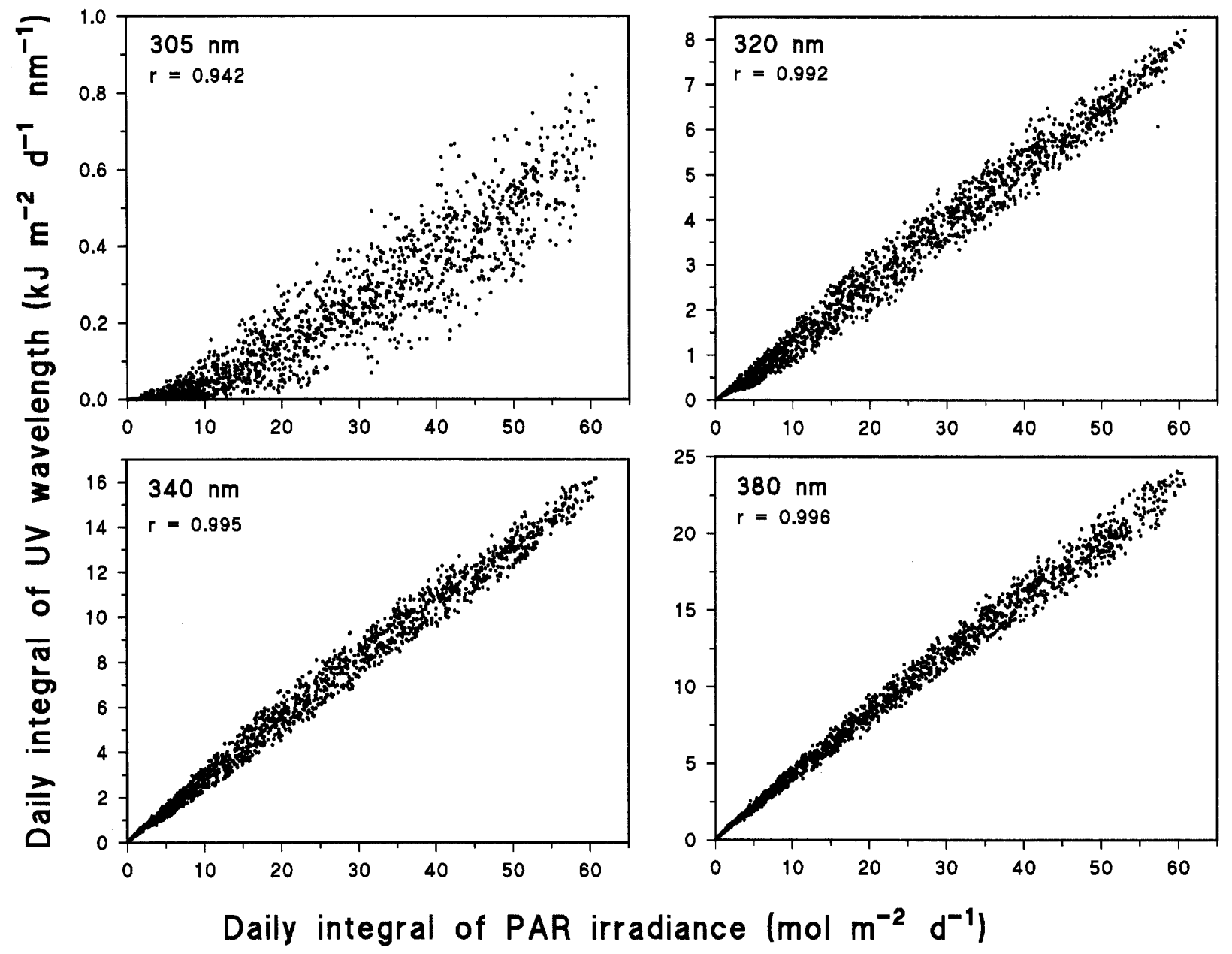

Fig. 3 Scatter diagrams of the daily integrals of UV radiation at each of four wavelengths $(305,320,340$ and $380 \mathrm{~nm})$ against the integral of PAR on the same day. The product-moment correlation coefficient for each wavelength is shown. The data for the whole measurement period are used, giving a sample size of about 1,800 for each panel

At any given time, the irradiance at each of the UV wavelengths was clearly correlated with the irradiance of PAR, and the relationship between each of the wavelengths and PAR is illustrated in Fig. 3, in which each daily integral of $305,320,340$ and $380 \mathrm{~nm}$ is plotted against the integral on the same day for PAR. The data for the three longest wavelengths showed a close fit to a linear regression, with $r$-values between 0.992 and 0.996 , but the data for $305 \mathrm{~nm}$ showed greater scatter $(r=0.942 ; 1,808 d f)$ and a marked departure from linearity (Fig. 3). This suggested that the ratio of $305-\mathrm{nm}$ to PAR radiation was not constant, and its variation with various factors was investigated and compared with that of the ratios of the other wavelengths to PAR.

The seasonal variation of the ratio between each UV wavelength and PAR was examined by calculating these ratios from the mean daily integrals for each month in the study. The $305 \mathrm{~nm}: \mathrm{PAR}$ ratio was about $0.002 \mathrm{mmol}$ $\mathrm{nm}^{-1} \mathrm{~mol}^{-1}$ PAR in December and January, but increased

through the spring to values around $0.028 \mathrm{mmol} \mathrm{nm}^{-1}$ $\mathrm{mol}^{-1}$ PAR in June and July, and then declined through the autumn (Fig. 4). This trend was apparent in all 6 years of the study, although consistently high summer values of the ratio were observed in some years (e.g. 1995) and low values were observed in other years (e.g. 1994, 1998). There was no evidence of an increase in the ratio of 305-nm radiation to PAR over the 6 years of the study, either for the year as a whole or for individual months or seasons. As suggested by the scatter plots in Fig. 2 and the maximum and minimum values in Table 1, the ratio of the other UV wavelengths to PAR did not vary so markedly through the year. The $320 \mathrm{~nm}$ :PAR ratio increased only by about $50 \%$ from winter to summer, the $340 \mathrm{~nm}: \mathrm{PAR}$ ratio was almost constant through the year, and the $380 \mathrm{~nm}:$ PAR ratio decreased slightly in the summer months (Fig. 4). The year-to-year variability (expressed as the coefficient of variation of the means for each month) of the three longer wavelengths to PAR was much less than that of the $305 \mathrm{~nm}$ :PAR ratio (Fig. 5).

In order to assess the influence of weather (cloud cover) on the relationship between UV wavelengths and PAR, the UV:PAR ratios were calculated separately for the six brightest and the six dullest days during the period 9 June- 8 July (i.e. in the 30 days centred on the 

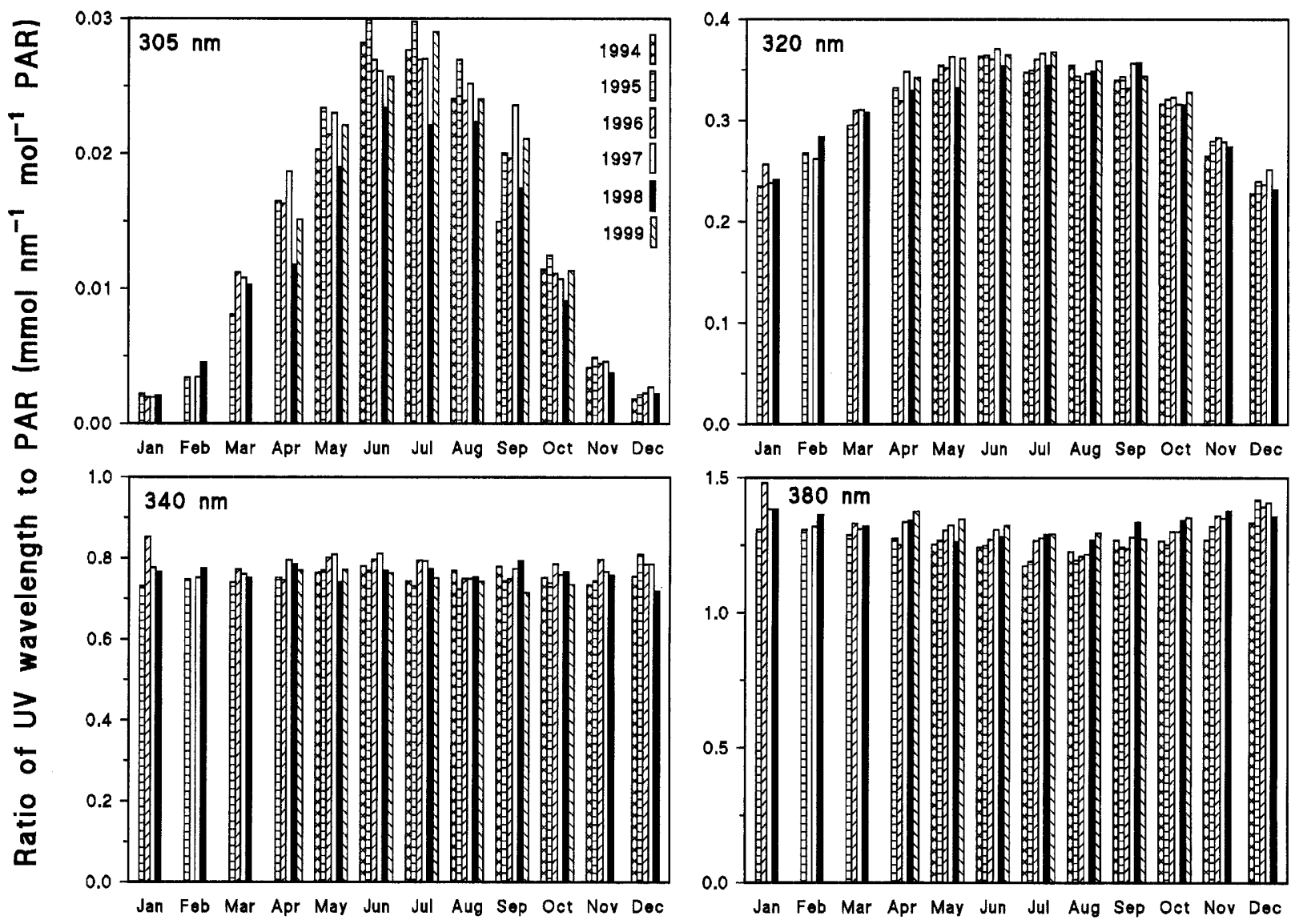

Fig. 4 Seasonal and year-to-year variations in the ratio of each UV wavelength $(305,320,340$ and $380 \mathrm{~nm})$ to PAR. Each histogram represents the UV:PAR ratio calculated from the mean of the daily integrals for the UV wavelength and PAR over each month in the study

summer solstice, when daylength is constant) for each of the years of the study. The ratios of 320,340 and $380 \mathrm{~nm}$ to PAR were $15-20 \%$ higher on the dull days than on the bright days, whereas the $305 \mathrm{~nm}$ :PAR ratio was not significantly different on dull and bright days (Fig. 6a). The influence of solar angle was assessed by calculating the same ratios on the brightest days (which were assumed to have clear skies) in the months centred on both solstices and both equinoxes (i.e. June, September, December and April). For all UV wavelengths, the ratio to PAR was highest in June and lowest in December, although the difference between these two months was greatest for $305 \mathrm{~nm}$ (December ratio=4\% of June ratio) and decreased with increasing wavelength to $380 \mathrm{~nm}$ (December ratio $=78 \%$ of June ratio; Fig. 6b). The values for April and September were similar, and were intermediate between the summer and winter values (Fig. 6b).

The influence of ozone concentration in the atmosphere was analysed by correlating the daily maximal irradiance in each UV waveband against the daily total column ozone for Helgoland predicted from total ozone mapping spectrometer satellite data. To avoid interference from cloud cover, the analysis was done only for

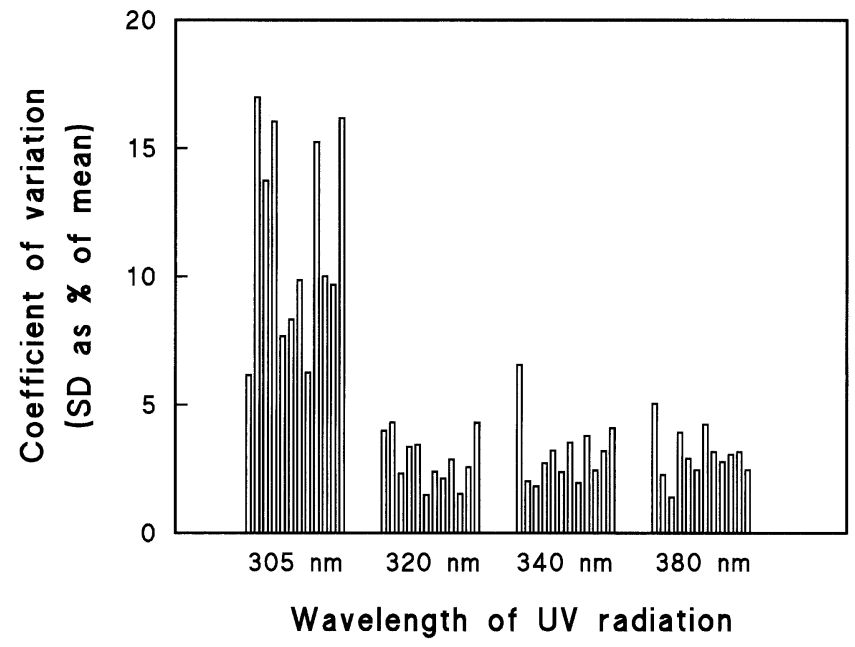

Fig. 5 Year-to-year variability in the ratios of each UV wavelength $(305,320,340$ and $380 \mathrm{~nm})$ to PAR in the daily integrals of surface radiation at Helgoland in 1994-1999. The ratios were calculated for each month of the study separately, and the histograms represent the coefficients of variation among years for each month of the year $(n=4-6)$

the brightest days in each season, as for the analysis of solar angle in Fig. 6b. The maximal daily irradiances at $305 \mathrm{~nm}$ showed a strong negative relationship with ozone in each season (Fig. 7), but the data for each season formed quite distinct clusters on the scatter diagram 

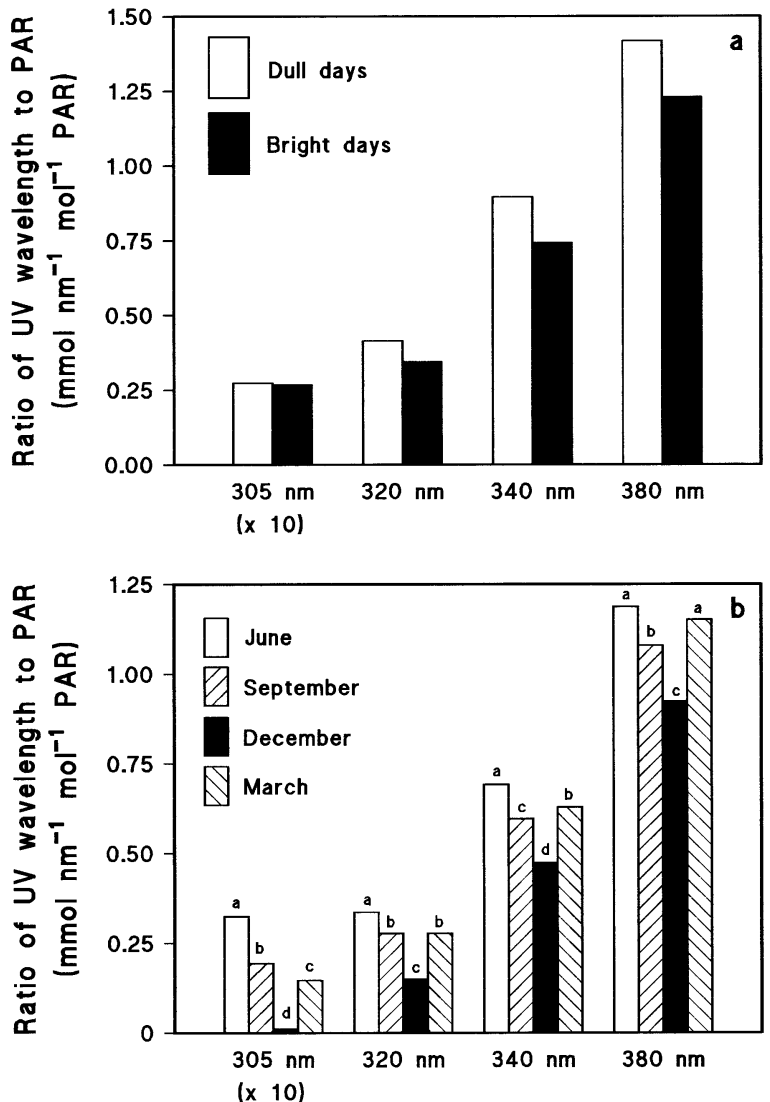

Fig. 6 Variations in the ratio of each UV wavelength $(305,320$, 340 and $380 \mathrm{~nm}$ ) to PAR with a cloud cover and b seasonal changes in solar angle. a Mean ratios based on daily integrals for the six brightest and six dullest days in June (i.e. with highest and lowest PAR integrals) in each year of the study. The differences between dull and bright days were highly significant for 320, 340 and $380 \mathrm{~nm}$, but non-significant for $305 \mathrm{~nm}$ (one-way ANOVA). b Mean ratios based on daily maximal irradiance for the brightest days in each of four 30-day periods centred on the two solstices and the two equinoxes. In each period, the means were calculated from all days, over the 6 years of the study, on which the maximal PAR irradiance exceeded a fixed value $\left(2,200 \mu \mathrm{mol} \mathrm{m} \mathrm{m}^{-2} \mathrm{~s}^{-1}\right.$ for June, $1,500 \mu \mathrm{mol} \mathrm{m}-2 \mathrm{~s}^{-1}$ for September and March, $385 \mu \mathrm{mol} \mathrm{m}-2$ $\mathrm{s}^{-1}$ for December). The letters above the histograms show the results of a multiple range test among the periods within each wavelength; histograms with different letters are significantly different at $P=0.05$

because the absolute irradiances of $305 \mathrm{~nm}$ were quite different. Since the PAR irradiances were high on all of these days (the days had been selected because the maximal PAR irradiance exceeded specific values in the four seasons; see legend to Fig. 7), the daily ratios of $305 \mathrm{~nm}$ to PAR were also strongly correlated with ozone, and showed much the same pattern as the absolute values for 305-nm irradiance (data not shown). In none of the other UV wavebands, however, was there a significant correlation between maximal daily irradiance and total column ozone.

The diurnal changes in UV irradiance and its relationship to PAR are illustrated by the data for two bright days, one in summer (7 July 1995; Fig. 8) and one in autumn (6 October 1995; Fig. 9). All four UV wavelengths

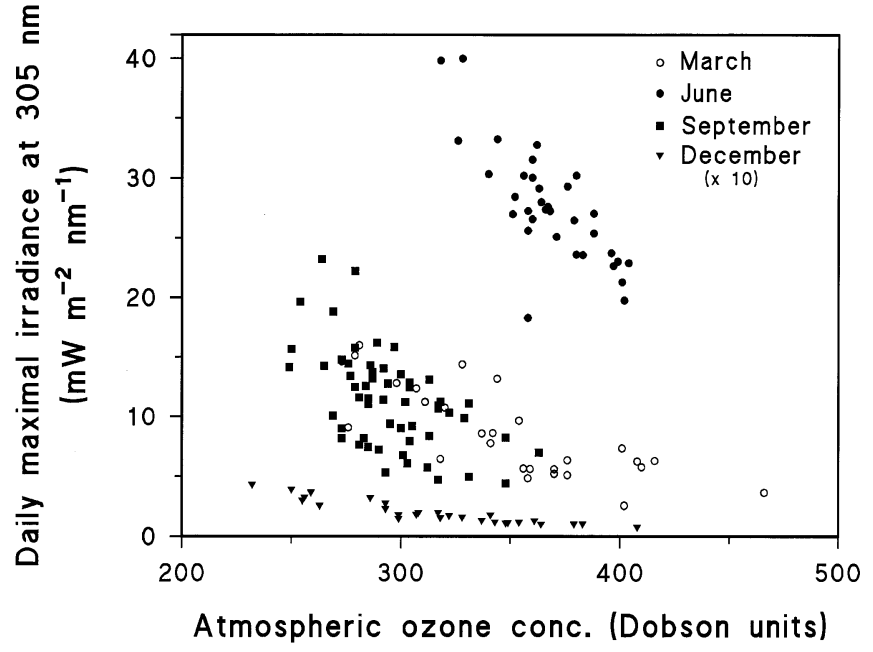

Fig. 7 Relationship between daily maximal irradiance at $305 \mathrm{~nm}$ and atmospheric ozone concentration (total column ozone, Dobson units) on the same days at Helgoland. Values are plotted for the brightest days in each of four 30-day periods centred on the two solstices and the two equinoxes in all years for which total ozone mapping spectrometer data are available (i.e. August 1996 to end of study). The "brightest days" were defined as all those on which the maximal PAR irradiance exceeded 2,000 $\mu \mathrm{mol} \mathrm{m}^{-2} \mathrm{~s}^{-1}$ in June, $1,200 \mu \mathrm{mol} \mathrm{m} \mathrm{m}^{-2} \mathrm{~s}^{-1}$ in September and March, $300 \mu \mathrm{mol} \mathrm{m} \mathrm{m}^{-2} \mathrm{~s}^{-1}$ in December. The negative correlation between the parameters was significant at $P=0.01$ for each of the four seasons
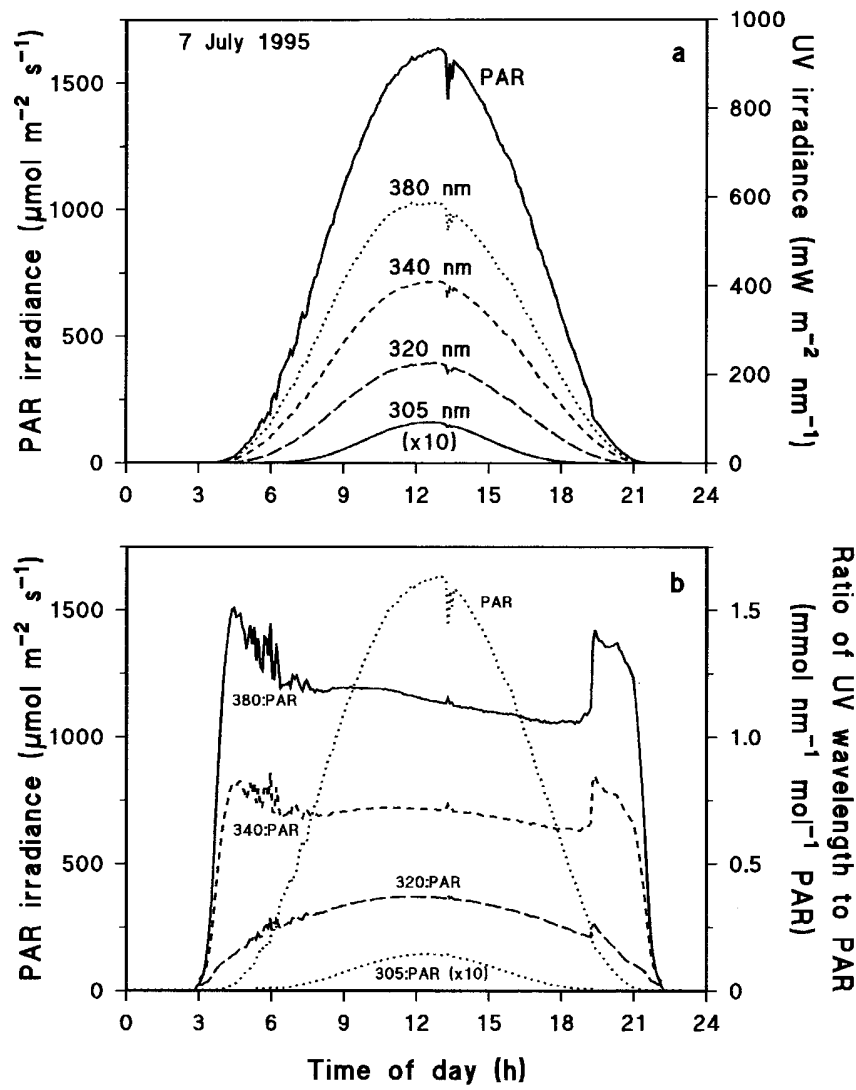

Fig. 8 a Diurnal variation in irradiance in each of four UV wavelengths (305, 320, 340 and $380 \mathrm{~nm}$; right-hand axis) and of PAR (left-hand axis) at Helgoland on 7 July 1995. b Diurnal variation in the ratio of each UV wavelength $(305,320,340$ and $380 \mathrm{~nm})$ to PAR calculated from simultaneous irradiance readings on 7 July 1995 

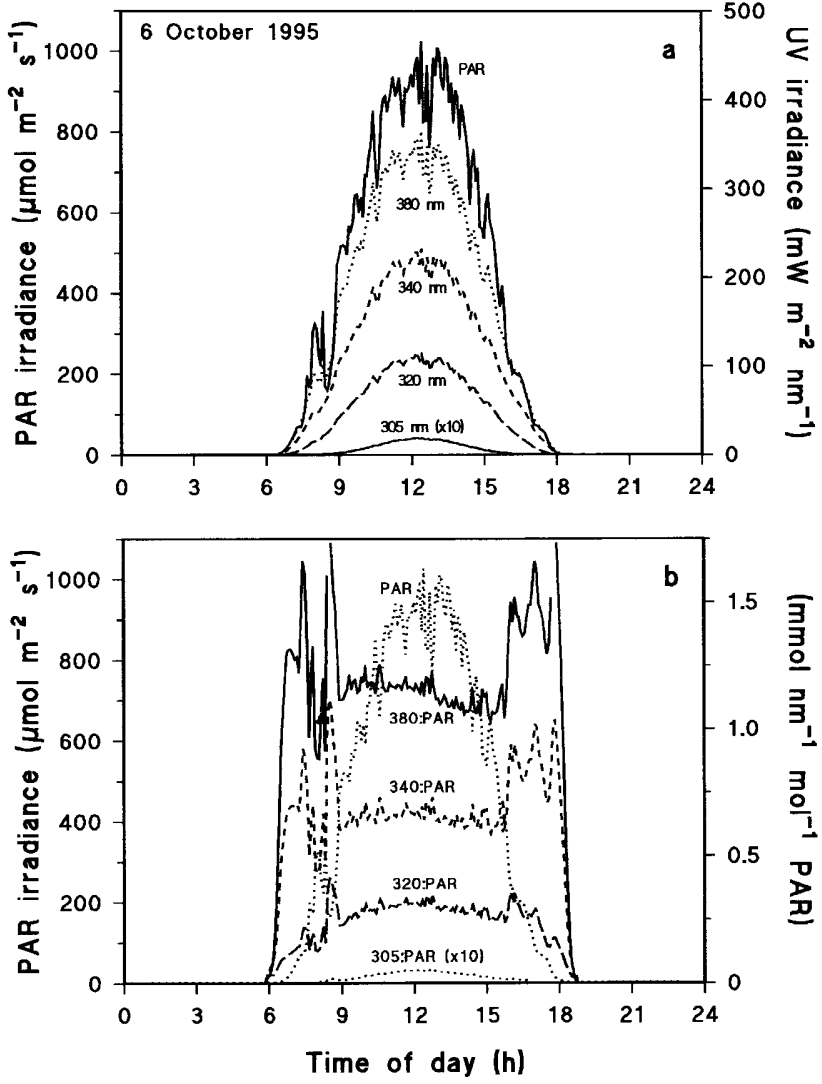

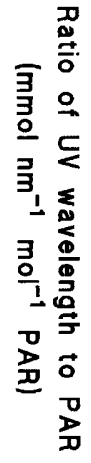

Fig. 9 a Diurnal variation in irradiance in each of four UV wavelengths (305, 320, 340 and $380 \mathrm{~nm}$; right-hand axis) and of PAR (left-hand axis) at Helgoland on 6 October 1995. b Diurnal variation in the ratio of each UV wavelength $(305,320,340$ and $380 \mathrm{~nm}$ ) to PAR calculated from simultaneous irradiance readings on 6 October 1995

followed the same bell-shaped curve as PAR, and mostly showed the same fluctuations due to occasional cloud cover (Figs. 8a, 9a). One feature of the summer curve (Fig. 8a) that requires explanation is the small but sudden drop in PAR irradiance at about $1920 \mathrm{~h}$. This occurred when the shadow of a cliff reached the sensor about 40 min before sunset and, for the rest of the day, only skylight was recorded. This feature is not apparent in the irradiance data for the UV wavelengths (Fig. 8a), but is prominent as a sharp increase in the ratios of 320-, 340- and 380-nm irradiance to PAR (Fig. 8b) at the time that the sensor became shadowed. The values of $380 \mathrm{~nm}:$ PAR and $340 \mathrm{~nm}$ :PAR were also high in the early morning in both July and October (Figs. 8b, 9b), although these two ratios were relatively low and constant through the middle of the day, when PAR was greater than about $250 \mu \mathrm{mol} \mathrm{m} \mathrm{m}^{-2} \mathrm{~s}^{-1}$. The ratios of 305 and $320 \mathrm{~nm}$ to PAR showed a stronger diurnal curve, with a maximum at midday, and little $(320 \mathrm{~nm})$ or no $(305 \mathrm{~nm})$ increase at the beginning and end of the day (Figs. 8b, 9b).

The vertical attenuation coefficient $\left(k, \mathrm{~m}^{-1}\right)$ was calculated for each UV wavelength and for PAR from profiles of underwater irradiance that were measured at approximately monthly intervals through the study. Mea-
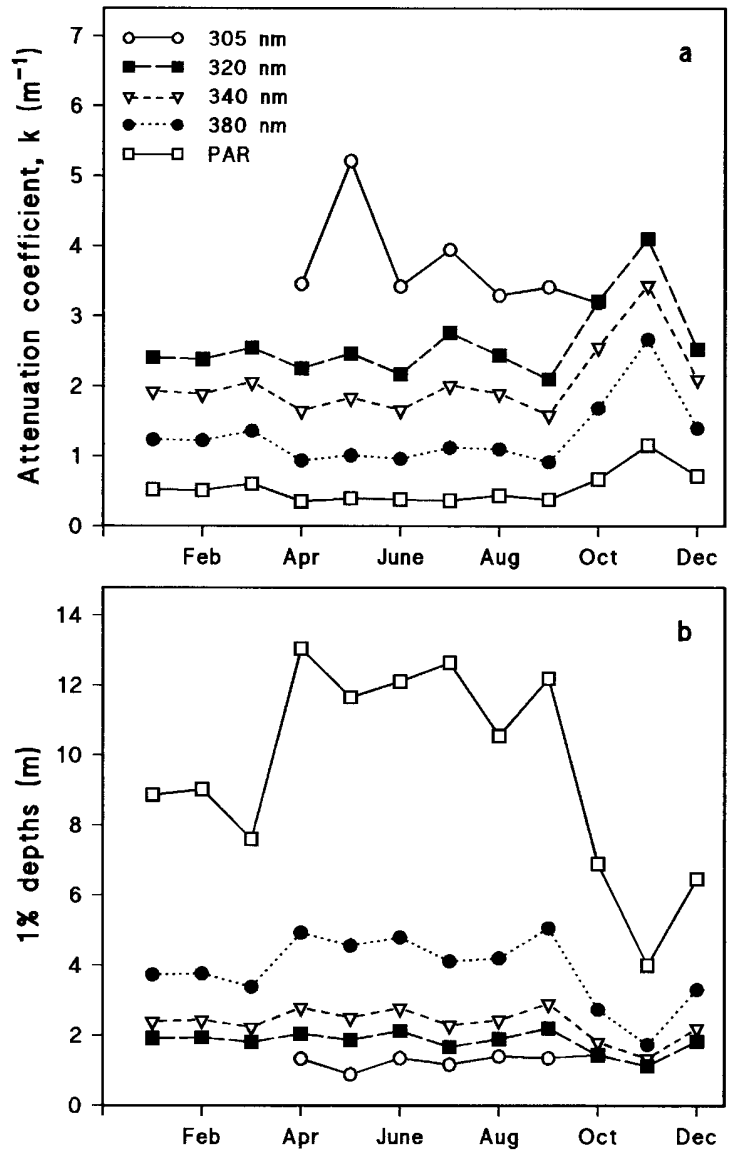

Fig. 10a, b Seasonal variation in penetration of four UV wavelengths $(305,320,340$ and $380 \mathrm{~nm})$ and of PAR through seawater off Helgoland during 1994-1999. Vertical profiles of irradiance in each waveband were measured at around midday on calm, bright days at approximately monthly intervals, and mean values for the attenuation coefficient (a) and the $1 \%$ depth (b) were calculated for each month from the data obtained over 6 years

surements were made only on calm days in sunny weather and in the middle of the day to maximise the depth of the profiles. The $k$-values obtained in any one month were averaged across the 6 years of the study and plotted against the month to show the seasonal variation (Fig. 10a). The lowest attenuation in all wavebands occurred between April and September, and the minimum monthly means recorded were 3.3 for $305 \mathrm{~nm}, 2.1$ for $320 \mathrm{~nm}, 1.6$ for $340 \mathrm{~nm}, 0.91$ for $380 \mathrm{~nm}$ and 0.35 for PAR. The $1 \%$ depths calculated from the attenuation coefficients are shown in Fig. 10b. The mean value of the $1 \%$ depth for $305 \mathrm{~nm}$ was $1.08 \mathrm{~m}$ but, since reliable measurements of underwater irradiance at this wavelength could be obtained only from April to October, this value overestimates the true annual mean. The annual means of the $1 \%$ depth for the other UV wavelengths were 1.54 , 2.00 and $3.28 \mathrm{~m}$ for 320,340 and $380 \mathrm{~nm}$, respectively. However, there was a marked increase in attenuation at all wavelengths in October and a recovery in April, so that the mean $1 \%$ depth in the summer months was closer to $2.0,2.6$ and $4.6 \mathrm{~m}$ for the same three wave- 
lengths. The corresponding mean $1 \%$ depths for PAR were $8.79 \mathrm{~m}$ for the whole year and $12.0 \mathrm{~m}$ for April to September.

\section{Discussion}

The long continuous series of irradiance measurements in this survey has provided a detailed picture of the irradiance of UV wavelengths at sea level on Helgoland over a 5- to 6-year period. The plots of daily maxima at 305 and $340 \mathrm{~nm}$ (Fig. 2) are comparable with the 3-year plots of noon irradiances in the wavebands 298-303 and 337-342 nm reported by Booth et al. (1994) for three Antarctic stations and one Arctic station during 1990-1992. Of these stations, Ushuaia in Argentina was closest in latitude to Helgoland, and the UV-B irradiances at the two sites (i.e. $305 \mathrm{~nm}$ for Helgoland and 298-303 nm for Ushuaia) are similar. However, the maximal irradiances at $340 \mathrm{~nm}$ for Helgoland were about one-fifth of the noon irradiances at 337-342 nm reported for Ushuaia (Booth et al. 1994). The reason for this discrepancy is not clear.

No significant inter-annual trends were apparent in the data, and there is no evidence that the reported thinning of the ozone layer over northern Europe in recent years (e.g. Pearce 1996) has had a measurable impact on levels of UV-B radiation at Helgoland. However, the total column ozone values for Helgoland that were determined for the analysis in Fig. 7 also provided no evidence for a decreasing trend over the years for which they were available (i.e. 1996-1999). Nevertheless, valuable information can be extracted about the seasonal and diurnal variations in the relationships among UV-B, UV-A and PAR. The constancy of the relationship between $340 \mathrm{~nm}$ and PAR, and between $380 \mathrm{~nm}$ and PAR, through the day (Figs. 8b, 9b) and through the seasons (Fig. 4), is remarkable. The greatest variations that were observed in the ratios of $340 \mathrm{~nm}: P A R$ and $380 \mathrm{~nm}: P A R$ were the increases of $15-20 \%$ that occurred at the beginning and end of sunny days (Figs. 8b, 9b) and on cloudy days in June (Fig. 6a). The end-of-day increases can be attributed to the increased contribution of skylight to the total radiation, and this effect was particularly well illustrated by the sharp increase in the $340 \mathrm{~nm}$ :PAR and $380 \mathrm{~nm}:$ PAR ratios when the sensor was covered by the shadow of a cliff on late summer evenings (Fig. 8). Scattering of the solar beam as it passes through the atmosphere is more intense at shorter wavelengths, and the quanta that are scattered in a forward direction will reach the surface as "skylight", which is therefore enriched in these shorter wavelengths (Kirk 1983).

It is probable that the increased $340 \mathrm{~nm}$ :PAR and $380 \mathrm{~nm}:$ PAR ratios that were observed on dull days in June (Fig. 6a) were also due to the increased proportion of skylight when the direct solar beam was intercepted by cloud cover. Whatever its cause, this effect was of the same magnitude as the decrease in the same ratios observed between sunny days in June and those in Decem- ber (Fig. 6b). Consequently, the combination of low solar angle with high cloudiness in winter and of high solar angle with clear skies in June could account for the observed constancy of these two ratios through the year.

The behaviour of the two shorter UV wavelengths relative to PAR are more difficult to explain. The proportions of both 305- and 320-nm radiation were more strongly dependent on solar angle, both through the day (Figs. 7, 8) and through the seasons (Fig. 4) than were those of 340- and 380-nm radiation. Consequently, UV-B wavelengths were more strongly represented in radiation at sea level around midday and during the summer months than they were early or late in the day or at other seasons. Stick et al. (1994) also observed that UV-B radiation was "disproportionately high in the midday sun". The greater dependence of shorter wavelengths on solar angle is probably due to the greater scattering of these wavelengths as the solar beam passes through the atmosphere (Roy et al. 1994), but little of this scattered radiation was measurable as skylight at the surface. There was no enhancement of $305 \mathrm{~nm}:$ PAR and little enhancement of $320 \mathrm{~nm}:$ PAR ratios in end-of-day radiation (Figs. 8b, $9 b)$, and cloudy conditions had no significant effect on the $305 \mathrm{~nm}:$ PAR ratio in June (Fig. 6b). As a result, there was no factor to offset the influence of solar angle, and the proportion of 305-nm radiation in natural daylight changed dramatically with time of day and with season. However, the high year-to-year variability of the $305 \mathrm{~nm}:$ PAR ratio (Fig. 5) suggests that this ratio is also more sensitive to climatic differences among years than are the ratios of the longer UV wavelengths to PAR.

The negative relationship between the maximal irradiance at $305 \mathrm{~nm}$ and the total column ozone that was observed on clear days in each season (Fig. 7) is exactly what would be expected from the well-known absorption of UV-B wavelengths by ozone. However, the quite separate clusters of data for each season show that solar angle exerts a greater influence than ozone, and that the irradiance of UV-B reaching the sea surface during the days with lowest ozone concentrations in winter and spring are no higher than those recorded in summer under ozone concentrations that are up to $60 \%$ greater (Fig. 7). Since "holes" in the ozone layer tend to occur in spring, when the solar angle is low, their significance for increasing the UV-B irradiance may be more limited than has often been supposed.

The clear implications of these results are that the amount of UV-A radiation in natural daylight can be estimated with reasonable accuracy from measurements of PAR, but that UV-B cannot be estimated so easily. However, the pattern of change of the $305 \mathrm{~nm}: \mathrm{PAR}$ ratio with time of day and season appears to be largely related to solar angle, so that it may be possible to model the relationship between 305-nm radiation and PAR. This would enable UV-B radiation at the surface to be estimated from PAR measurements.

The ratio between UV radiation and PAR undergoes further changes as natural daylight penetrates below the surface of the sea, and the data collected in this study 
confirm the results of previous studies (e.g. Højerslev 1978; Piazena and Häder 1994), conducted over shorter periods, that measurable amounts of UV-B radiation do not penetrate beyond the top metre in the southern North Sea and Baltic Sea. The mean attenuation coefficient for $305 \mathrm{~nm}$ during the summer months was about 3.5 (Fig. 10a), which is close to values determined for $310 \mathrm{~nm}$ by Højerslev (1988) in the Baltic Sea (3.0-3.5) and within the range reported for the German Bight (0.53-5.0), although higher than values in the Kattegat (1.2-2.3) and Skaggerak (0.6-1.2). Kirk (1994) and Franklin and Forster (1997) have tabulated attenuation coefficients and penetration depths for UV-B in a range of marine locations, and the values recorded in the present study suggest that UV-B penetration in the waters around Helgoland is weaker than at any other site that has been studied, with the exception of Hiddensee Island in the Baltic, where the attenuation coefficient for the 290-320 nm waveband was >5 (Piazena and Häder 1994). There are fewer data available on the penetration of UV-A radiation [see Table 1 in Franklin and Forster (1997)] but, again, the waters around Helgoland appear to be more effective than most in excluding UV radiation.

Attempts to assess the ecological impact of UV-B on marine organisms must take into account the diurnal and seasonal variations in the irradiances experienced when organisms are emersed, and the moderating influence of the overlying seawater when they are submersed. The strong attenuation of UV-B radiation by the seawater around Helgoland suggests that benthic organisms growing at mid-tide level or below will receive measurable amounts of UV-B radiation only for short periods of time at low water. Since the low waters of spring tides occur at Helgoland in the morning and the evening, and the $305 \mathrm{~nm}$ :PAR ratio is low at these times, the exposure to UV-B is likely to be quite modest, and less than that often used in laboratory experiments examining the influence of UV radiation on marine organisms [e.g. the maximal irradiance received in summer is often used as an "ecologically relevant" irradiance for laboratory exposures; Dring et al. (1996a, 1996b)]. The only marine organisms that receive prolonged exposure to UV-B irradiances similar to those used in laboratory experiments are macroalgae from the upper half of the intertidal zone, many of which have been shown to be insensitive to UV-B exposure (e.g. Dring et al. 1996b; Franklin and Forster 1997).

Acknowledgement This research was supported by a grant from the German Federal Ministry for Training and Research on "UV effects on marine organisms".

\section{References}

Booth CR, Lucas TB, Morrow JH, Weiler CS, Penhale PA (1994) The United States National Science Foundation's Polar Network for Monitoring Ultraviolet Radiation. Antarct Res Ser 62:17-37

Dring MJ, Makarov V, Schoschina E, Lorenz M, and Lüning K (1996a) Influence of ultraviolet radiation on chlorophyll fluorescence and growth in different life history stages of three species of Laminaria (Phaeophyta). Mar Biol 126:183-191

Dring MJ, Wagner A, Boeskov J, and Lüning K (1996b) Sensitivity of intertidal and subtidal red algae to UVA and UVB radiation, as monitored by chlorophyll fluorescence measurements: influence of collection depth and season, and length of irradiation. Eur J Phycol 31:293-302.

Franklin LA, and Forster RM (1997) The changing irradiance environment: consequences for marine macrophyte physiology, productivity and ecology. Eur J Phycol 32:207-232

Højerslev NK (1988) Natural occurrence and optical effects of Gelbstoff. Report no. 50. Geofysisk Institut, University of Copenhagen, Copenhagen

Kirk JTO (1983) Light and photosynthesis in aquatic ecosystems. Cambridge University Press, Cambridge

Kirk JTO (1994) Optics of UV-B radiation in natural waters. Arch Hydrobiol Beih Ergebn Limnol 43:1-16

Pearce F (1996) Big freeze digs a deeper hole in ozone layer. New Sci 149:7

Piazena H, and Häder DP (1994) Penetration of solar UV irradiation in coastal lagoons of the southern Baltic Sea and its effect on phytoplankton communities. Photochem Photobiol 60:463469

Roy CR, Gies HP, Tomlinson DW, and Lugg DL (1994) Effects of ozone depletion on the ultraviolet radiation environment at the Australian stations in Antarctica. Antarct Res Ser 62:1-15

Stick C, Harms V, and Pielke L (1994) Measurements of solar ultraviolet irradiance with respect to the human body surface. Soc Photo-Opt Instrum Eng Proc Ser 2134B:129-134

Wängberg S, Selmer J, Ekelund NGA, and Gustavson K (1996) UVB effects on Nordic marine ecosystem - a literature review. TemaNord 1996:515. Nordic Council of Ministers, Copenhagen 